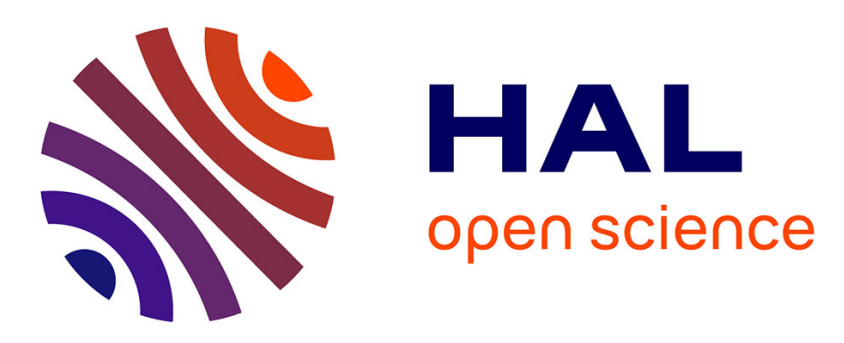

\title{
Repair of calvarial bone defects in mice using electrospun polystyrene scaffolds combined with $\beta$-TCP or gold nanoparticles
}

\author{
Lisa Terranova, Diana Dragusin, Romain Mallet, Eugeniu Vasile, \\ Izabella-Cristina Stancu, Catherine Behets, Daniel Chappard
}

\section{To cite this version:}

Lisa Terranova, Diana Dragusin, Romain Mallet, Eugeniu Vasile, Izabella-Cristina Stancu, et al.. Repair of calvarial bone defects in mice using electrospun polystyrene scaffolds combined with $\beta$-TCP or gold nanoparticles. Micron (Oxford, England: 1993), 2017, 93, pp.29-37. 10.1016/j.micron.2016.11.001 . hal-02869281

\section{HAL Id: hal-02869281 \\ https://univ-angers.hal.science/hal-02869281}

Submitted on 15 Jun 2020

HAL is a multi-disciplinary open access archive for the deposit and dissemination of scientific research documents, whether they are published or not. The documents may come from teaching and research institutions in France or abroad, or from public or private research centers.
L'archive ouverte pluridisciplinaire HAL, est destinée au dépôt et à la diffusion de documents scientifiques de niveau recherche, publiés ou non, émanant des établissements d'enseignement et de recherche français ou étrangers, des laboratoires publics ou privés. 
Tutorial

\title{
Repair of calvarial bone defects in mice using electrospun polystyrene scaffolds combined with $\beta$-TCP or gold nanoparticles
}

\author{
Lisa Terranova $^{\mathrm{a}, \mathrm{c}}$, Diana Maria Dragusin ${ }^{\mathrm{d}}$, Romain Mallet ${ }^{\mathrm{a}, \mathrm{b}}$, Eugeniu Vasile ${ }^{\mathrm{e}}$, Izabela-Cristina Stancu ${ }^{\mathrm{d}}$, \\ Catherine Behets $^{\mathrm{c}}$, Daniel Chappard ${ }^{\mathrm{a}, \mathrm{b}, *}$ \\ a GEROM Groupe Etudes Remodelage Osseux et bioMatériaux - LabCom NextBone, IRIS-IBS Institut de Biologie en Santé, CHU d'Angers, Université d'Angers, 49933 Angers \\ Cedex, France \\ b SCIAM, Service Commun d'Imagerie et Analyses Microscopiques, IRIS-IBS Institut de Biologie en Santé, CHU d'Angers, Université d'Angers, 49933, Angers Cedex, France \\ c Pôle de Morphologie, Institut de Recherche Expérimentale et Clinique, Université catholique de Louvain, 1200 Brussels, Belgium \\ d Advanced Polymer Materials Group, Faculty of Applied Chemistry and Materials Science, Faculty of Medical Engineering, University Politehnica of Bucharest, 1-7 Gh Polizu \\ Street, Sector 1, 011061, Bucharest, Romania

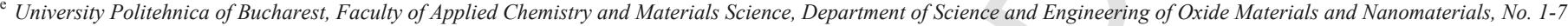 \\ Gh Polizu Street, 011061, Bucharest, Romania
}

\section{A R T I C L E I N F O}

Article history:

Received 3 October 2016

Received in revised form 4 November 2016

Accepted 4 November 2016

Available online xxx

Keywords:

Polystyrene fibers

$\beta$-TCP

Gold nanoparticles

Electrospinning

Cytocompatibility

Biocompatibility

\section{A B S T R A C T}

Non-biodegradable porous polystyrene (PS) scaffolds, composed of microfibers, have been prepared by electrospinning for the reconstruction of large bone defects. PS microfibers were prepared by incorporating $\beta$-TCP grains inside the polymer or grafting gold nanoparticles surface functionalized with mercaptosuccinic acid. Cytocompatibility of the three types of scaffolds (PS, $\beta$-TCP-PS and Au-PS) was studied by seeding human mesenchymal stem cells. Biocompatibility was evaluated by implanting $\beta$-TCP-PS and Au-PS scaffolds into a critical size $(4 \mathrm{~mm})$ calvarial defect in mice. Calvaria were taken 6,9, and 12 weeks after implantation; newly formed bone and cellular response was analyzed by microcomputed tomography (microCT) and histology.

$\beta$-TCP-PS scaffolds showed a significantly higher cell proliferation in vitro than on PS or Au-PS alone; clearly, the presence of $\beta$-TCP grains improved cytocompatibility. Biocompatibility study in the mouse calvaria model showed that $\beta$-TCP-PS scaffolds were significantly associated with more newly-formed bone than Au-PS. Bone developed by osteoconduction from the defect margins to the center. A dense fibrous connective tissue containing blood vessels was identified histologically in both types of scaffolds. There was no inflammatory foci nor giant cell in these areas. AuNPs aggregates were identified histologically in the fibrosis and also incorporated in the newly-formed bone matrix. Although the different types of PS microfibers appeared cytocompatible during the in vitro experiment, they appeared biotolerated in vivo since they induced a fibrotic reaction associated with newly formed bone.

(C) 2016 Published by Elsevier Ltd.

\section{Introduction}

Reconstruction of massive bone defects caused by diseases or traumas (bone cysts, osteolysis after total hip reconstruction, neurosurgical defects, tumor ablation) is a current challenge in orthopedic

Abbreviations: $\beta$-TCP, beta tricalcium phosphate; $\beta$-TCP-PS, polystyrene scaffold blended with $\beta$-TCP; AuNPs, gold nanoparticles; Au-PS, polystyrene scaffold decorated with gold nanoparticles; $\mathrm{BAr} / \mathrm{TAr}$, bone area/total area; DMF, $N, N$-dimethylformamide; EDS, energy X-ray dispersive spectroscopy; FTIR, fourier transform infrared spectroscopy; hMSC, human mesenchymal stem cells; MicroCT, X-ray microcomputed tomography; MSA, mercaptosuccinic acid; PS, polystyrene; SEM, scanning electron microscopy; UCL, Université Catholique de Louvain

* Corresponding author at: GEROM Groupe Etudes Remodelage Osseux et bioMatériaux - LabCom NextBone, IRIS-IBS Institut de Biologie en Santé, CHU d'Angers, Université d'Angers, 49933 ANGERS Cedex, France.

Email address: daniel.chappard@univ-angers.fr (D. Chappard) surgery, oral and maxillofacial surgery. Grafting autologous bone is widely used due to its excellent osteoconductive and mechanical properties (Dimitriou et al., 2011; Younger and Chapman, 1989). However, it requires an additional surgical site leading to an increased morbidity and is necessarily limited in volume. Synthetic osteoconductive materials are developed as an alternative and must fulfill well-defined specifications when in contact with biological tissues and fluids. Three dimensional (3D) scaffolds of polymer have been proposed to repair a variety of large bone defects. Polymers are an interesting choice because their synthesis can be controlled and various methods have been developed to create 3D porous scaffolds with a controlled architecture. Electrospinning is a promising method to prepare polymer fibers and arrange them into porous 3D scaffolds. Electrospinning produces scaffolds of fibers with a diameter ranging from ten nanometers to a few micron (Ma et al., 2005). Such scaffolds mimic the morphology of the extracellular matrix (ECM), which supports cell proliferation. Scaffolds offer a large surface area per volume ratio to ensure cell infiltration, spreading, and proliferation. The 
interconnected porosity also promotes angiogenesis which is responsible for the transport of osteoprogenitor cells, oxygen, and nutrients to the grafted site (Brandi and Collin-Osdoby, 2006). Polystyrene (PS), a non-resorbable and cytocompatible polymer, was electrospun to produce microfibers. PS scaffolds seem a promising solution to support bone regeneration in cases of large size bone defect. We have previously shown that PS fibers promote cell proliferation and differentiation in vitro (Baker et al., 2006; Serafim et al., 2014; Terranova et al., 2016).

The aim of this study was to develop scaffolds of PS fibers alone or combined with an additional osteoconductive material: gold or beta tricalcium phosphate $(\beta-\mathrm{TCP})$. $\beta$-TCP is a well-known biocompatible ceramic, its chemical composition and crystallinity are close to the mineral phase of bone and confer excellent osseointegration properties (Chappard et al., 2010). $\beta$-TCP incorporated in natural or synthetic polymers increases their biocompatibility (Lao et al., 2011; Park et al., 2016). Gold nanoparticles (AuNPs) show biocompatibility and non-cytotoxicity (Sperling et al., 2008). They present a particular interest for nanotechnology research in biology due to their small size, high surface-to-volume ratio, and an easy surface modification through various functional amine or thiol groups. AuNPS were proposed as a contrasting agent for in vivo X-ray tomography, drug and gene delivery and biosensing (Sperling et al., 2008). AuNPs provide the advantage to have antioxidant effects by inhibiting reactive oxygen species and reactive nitrite species (Shukla et al., 2005). For bone application, surfaces decorated with thiol functional groups may stimulate apatite formation in vivo (Vasile et al., 2012). Scaffolds of $\beta$-TCP-PS and Au-PS fibers were prepared and characterized by scanning electron microscopy (SEM). They were seeded with human mesenchymal stem cells (hMSC) to analyze cytocompatibility in vitro. Scaffolds of PS, $\beta$-TCP-Ps and Au-PS were studied in the critical-size calvarial bone defect model in mice to evaluate the biocompatibility (An and Freidman, 1999). The healing of bone defect was evaluated by X-ray microcomputed tomography (microCT) and histology.

\section{Material and methods}

\subsection{Preparation of PS scaffolds by electrospinning}

\subsubsection{Preparation of PS scaffolds}

Electrospinning conditions of PS scaffolds were determined in a previous study (Terranova et al., 2016). PS fibers were produced by electrospinning using an Electrospinner x.x.S/D-500 (YFlow, Malaga, Spain). The polymer solution was prepared at a concentration of $30 \%$ (w/v) in $N, N$-dimethylformamide (DMF, Sigma). The polymer solution was loaded into a $10 \mathrm{~mL}$ plastic syringe controlled by a pump at $5 \mathrm{~mL} / \mathrm{h}$. A Teflon tube was connected from the syringe to a needle (inner diameter: $0.6 \mathrm{~mm}$ ) disposed vertically. A $15 \mathrm{kV}$ high voltage power supply was applied to the solution to induce a charge on the surface of the polymer droplet at the tip of the needle. When a critical voltage is reached, the droplet elongates and a solution jet is ejected to a collector. The distance between the needle and the collector was maintained at $10 \mathrm{~cm}$. Aligned fibers were produced with a drum collector with a rotation of $2400 \mathrm{rpm}$. After one hour, a thin sheet of microfibers could be detached from the collector and used for further analysis.

\subsubsection{Preparation of Au-PS scaffolds}

PS fibers were decorated with AuNPs from a modified protocol starting from chloroauric acid using a modified citrate reduction method (Storhoff et al., 1998). Briefly, $68 \mu \mathrm{L} 4 \mathrm{wt} \%$ gold(III) aqueous solution were added in a $50 \mathrm{~mL}$ flask placed on a magnetic stir- rer. They were further diluted with $10 \mathrm{~mL}$ of a $50 \mathrm{v} / \mathrm{v} \% \mathrm{EtOH}$ aqueous solution. The resulting gold(III) solution was heated up to $70{ }^{\circ} \mathrm{C}$ using a water bath and a $12 \mathrm{~cm}^{2}$ PS sheet was immersed into this solution while stirring. After $10 \mathrm{~min}, 1 \mathrm{~mL}$ of $1 \%$ trisodium citrate aqueous solution was added and stirring was continued for $6 \mathrm{~h}$ after the solution has turned deep violet. The gold-coated polymer microfibers were rinsed with a $50 \mathrm{v} / \mathrm{v} \%$ ethanol aqueous solution. The microfibers were further immersed in $1 \mathrm{mM}$ ethanolic solution of mercaptosuccinic acid (MSA), for $24 \mathrm{~h}$ at room temperature. Then, extensive washing with ethanol was performed to remove excess acid. At this step, the Au-PS fibers had a purple-violet color due to the presence of the AuNPs.

\subsubsection{Preparation of $\beta$-TCP-PS scaffolds}

PS microfibers containing $\beta$-TCP particles were prepared by electrospinning by adding $\beta$-TCP particles (Kasios, L'Union, France) $(20 \% \mathrm{w} / \mathrm{v})$ in the DMF. Sonication for 15 min ensured a homogeneous suspension. PS was then added at the same concentration than above. The solution was finally sonicated again for $30 \mathrm{~min}$ to disrupt possible agglomerates and electrospun as described above.

\subsection{Characterization of the PS scaffolds}

Surface morphology of the different fibers was determined by SEM on a JEOL 6301F (JEOL Paris, France) using the secondary electron mode. The backscattered electron mode was also used on a SEM (EVO LS10, Carl Zeiss Ltd., Nanterre, France) for $\beta$-TCP-PS. Au-PS were analyzed on a QUANTA INSPECT F SEM with $1.2 \mathrm{~nm}$ resolution. Microfibers were coated with a thin layer of carbon by sputtering with a high vacuum coater (Leica EM ECA600, Leica, France). Images were captured at $3 \mathrm{kV}$ acceleration voltage in the secondary electron mode and a working distance of $13 \mathrm{~mm}$. Energy X-ray dispersive spectrometry (EDS) was used to characterize the presence of calcium-phosphate on $\beta$-TCP-PS and gold on the Au-PS microfibers.

\subsection{Surface characterization of Au-PS and $\beta$-TCP-PS scaffolds}

For the Au-PS fibers, attenuated total reflectance (ATR)/Fourier transform infrared spectroscopy (FTIR) was used to identify the presence of the carboxyl-surface functionalization of the microfibers. FTIR was done using a Jasco 4200 spectrometer equipped with a Specac Golden Gate ATR device, at a resolution of $4 \mathrm{~cm}^{-1}$ and an accumulation of 100 spectra, in the $4000-600 \mathrm{~cm}^{-1}$ wavenumber region.

Raman spectroscopy was used to characterize the presence of phosphate groups on the $\beta$-TCP-PS microfibers. Analysis were performed on a Senterra microscope with a $523 \mathrm{~nm}$ excitation laser wavelength, excitation power of $50 \mathrm{~mW}$ and $3-5 \mathrm{~cm}^{-1}$ resolution. The OPUS 5.5 software (Bruker optic, Ettlingen) was used to collect the spectra. The final spectra were obtained by averaging five scans acquired during $40 \mathrm{~s}$.

\subsection{Culture of human mesenchymal stem cells}

Human mesenchymal stem cells (hMSC) were obtained from Promocell and cultured in DMEM (Dulbecco's Modified Eagle Medium) supplemented with $10 \%$ fetal bovine serum and $1 \%$ penicillin-streptomycin. The medium was replaced every 2 or 3 days and the culture was maintained in a humidified atmosphere with $5 \% \mathrm{CO}_{2}$ at $37^{\circ} \mathrm{C}$. The scaffolds were cut into circular disks $(20 \mathrm{~mm}$ in diameter) and placed in 12 well tissue culture plates. The disks were sterilized in $70 \%$ ethanol during three hours. They were then washed several times in sterile PBS and immersed in DMEM for a night. 
To evaluate cell proliferation, hMSC cells were seeded on the scaffolds at a concentration of $2 \times 10^{4}$ cells $/ \mathrm{mL}$, and cultured during 1 , 3 , and 7 days. The culture medium was refreshed every two or three days. At each time point, the number of viable and attached cells was determined by MTT assay. MTT assay is based on the reaction of mitochondria of the metabolically active cells with a tetrazolium salt (MTT 3-(4,5-dimethylthiazol-2-yl)-2,5-diphenyltetrazolium bromide, Sigma Aldrich). Cells were incubated with MTT solution at a concentration of $0.5 \mathrm{mg} / \mathrm{mL}$ in PBS for $3 \mathrm{~h}$ with $5 \% \mathrm{CO}_{2}$ at $37^{\circ} \mathrm{C}$. Tetrazolium salt was reduced in purple formazan crystals which were then dissolved in acidified isopropanol. Supernatant was transferred in 96 well plates and absorbance was read at $570 \mathrm{~nm}$ with a spectrophotometric plate reader (Molecular Device, SpectraMax M2). Absorbance is proportional to the number of viable cells. Analysis was done in triplicate for each type of scaffold.

\subsection{In vivo implantation of scaffolds in calvarial bone defects}

Forty five female NMRI mice (8-9 weeks of age) from the UCL animal facility were used as recipient. All animal experiments were performed in accordance with the Animal Care and Use Committee guidelines of the UCL (reference 2014/UCL/MD/021). Mice were anesthetized by an intraperitoneal injection (ketamine-xylazine). Skin was incised on the midline from the occipital to the frontal bone and the underlying periosteum was removed. A full-thickness calvarial defect (4 $\mathrm{mm}$ in diameter) in the non-suture right parietal bone was created under physiological saline irrigation with a round bur $(1 \mathrm{~mm}$ in diameter) fixed in a dental handpiece (EM 2900, GD, Italy). The calvarial disks were carefully removed to keep the dura matter as intact as possible. Sterilized $\beta$-TCP-PS or Au-PS scaffolds (diameter $4 \mathrm{~mm}$ ) were extensively rinsed in PBS and placed into the defect. In control mice, the defect was left unfilled. The skin was closed with a 4.0 polydioxanon suture (Ethicon). Mice were euthanized by isoflurane inhalation after 6, 9 and 12 weeks. The head was taken and fixed in $10 \%$ buffered formalin. At each time, 5 implanted mice were compared with 5 control mice.

\subsection{Microcomputed tomography}

MicroCT analysis of the calvaria was performed at each time point with a Skyscan 1172 X-ray computed microtomograph (Bruker MicroCT, Kontich, Belgium). Each calvaria, still in the fixative to prevent desiccation, was scanned at $70 \mathrm{kV}, 100 \mu \mathrm{A}$ and with a $0.5 \mathrm{~mm}$ aluminum filter. The pixel size was fixed at $10 \mu \mathrm{m}$ and a $0.25^{\circ}$ rotation angle was applied at each step. For each bone, a stack of $2 \mathrm{D}$-sections was obtained. The CTVox Software (Skyscan, release 3.2.0) was used for the reconstruction of the whole 3D models. New bone formation within the defect was measured from $3 \mathrm{D}$ reconstruction images using Image $\mathrm{J}$ on the inner side of the calvaria. A ROI was drawn around the initial defect, and the resulting image was thresholded. The fractional area (BAr/TAr, in \%) was determined as the ratio between the ROI and the detected new bone; the nomenclature follows the recommendation of the ASBMR (Dempster et al., 2013).

\subsection{Histological analysis}

Calvaria were decalcified for two days in OsteoRAL (RAL diagnostics, Martignac, France), dehydrated in graded methanol solutions and embedded in paraffin using a Sakura Tissue Tek VIP 5 Tissue Processor. Serial $5 \mu \mathrm{m}$-thick sections, were prepared and stained with Masson's trichrome and picrosirius red.

\subsection{Statistical analysis}

Statistical analysis was performed using the Systat statistical software release 13.0 (Systat Software Inc., San José, CA). All data are expressed as mean \pm standard deviation. Differences were analyzed by a non-parametric ANOVA (Kruskall-Wallis) followed by the Conover-Inman test for all pairwise comparisons. Differences were considered significant when $\mathrm{p}<0.05$.

\section{Results}

No complication occurred in the animals after the implantation surgery (such as hematoma, bleeding or hypertrophic scar). Unfortunately, three mice of the Au-PS group at 12 weeks died from an unrelated cause, making this group unsuitable for analysis.

\subsection{Characterization of PS scaffolds by SEM}

Scaffolds were composed of microfibers oriented in the same direction, although some fibers were incidentally disoriented (Fig. 1). Microporosity was in the form of interconnected voids between the fibers conditioned by the fibers diameter. Scaffolds measured $500 \mu \mathrm{m}$ in thickness and fibers had a mean diameter of $4 \mu \mathrm{m}$. $\beta$-TCP-PS fibers exhibited a rough appearance with grains of $\beta$-TCP embedded in the polymer; numerous grains were exposed at the surface of the fibers. In the backscattered electron mode, the chemical contrast clearly identified all $\beta$-TCP grains which were regularly dispersed along the PS fibers. AuNPs were also clearly identified at the surface of the Au-PS microfibers. These latter appeared regularly coated by the AuNPs which could easily be identified in the backscattered electron mode.

\subsection{Surface characterization of Au-PS scaffolds}

FTIR spectra (Fig. 2) evidenced the carboxyl-surface functionalization of AuNPs deposited on the fibers. The control samples MSA presented broad vibrations assigned to hydrogen bonded $\mathrm{O}-\mathrm{H}$ combined with superimposed $\mathrm{C}-\mathrm{H}$ stretching vibrations in the wavenumber interval $3300-2300 \mathrm{~cm}^{-1}$ (this part of the spectra was cut to concentrate on the $2000-600 \mathrm{~cm}^{-1}$ interval), carboxylate vibrations in the range $1700-1540 \mathrm{~cm}^{-1}$ and $1500-1445 \mathrm{~cm}^{-1}$ and $\mathrm{C}-\mathrm{S}$ stretch at $676 \mathrm{~cm}^{-1}$. The spectrum of Au-PS (PS coated with MSA-treated AuNPs) suggested the $-\mathrm{COOH}$-functionalization of the nanoparticles present on the surface of the fibers. Different spectral modifications were noticed when compared to the two control materials. The main features of the PS substrate were maintained: $1600-1450 \mathrm{~cm}^{-1}$ aromatic $\mathrm{C}=\mathrm{C}$ stretching bands, and a small new peak appearing at $1543 \mathrm{~cm}^{-1}$ proved the immobilization of the alkanethiol, assigned to carboxylate vibration of carboxylic acid originated from MSA. Furthermore, a new peak at $661 \mathrm{~cm}^{-1}$ is visible in the spectrum of Au-PS, and it is assigned to the C-S strech, proving the presence of the MSA residues on the surface of the AuNPs.

Raman spectra of $\beta$-TCP grains, PS fibers and $\beta$-TCP-PS fibers are shown in Fig. 2. The spectra of $\beta$-TCP grains exhibited the characteristic phosphate peaks at 948 and $960 \mathrm{~cm}^{-1}$. The spectra of PS fibers exhibited a peak related to aromatic ring deformation at $621 \mathrm{~cm}^{-1}$, two peaks related to $\mathrm{CH}$ deformation of mono-substituted aromatic ring at 1000 and $1031 \mathrm{~cm}^{-1}$. The peak at $1155 \mathrm{~cm}^{-1}$ corresponded to the $\mathrm{CC}$ stretch of alkane. The peaks observed on the $\beta$-TCP-PS fibers spectra evidenced the major peaks of both components $\beta$-TCP and PS. 

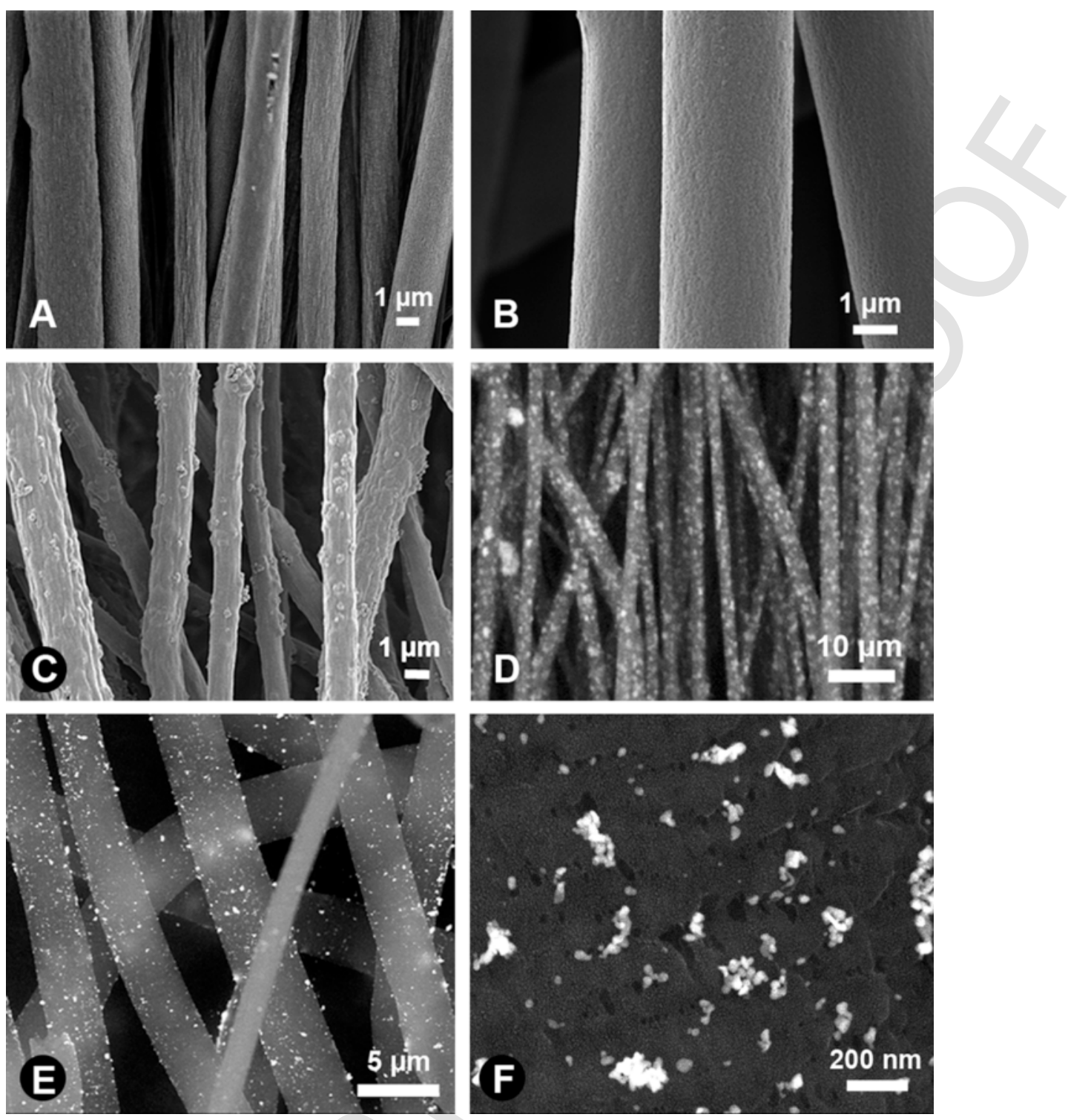

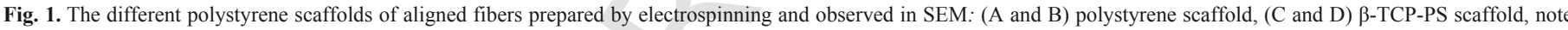
the $\beta$-TCP grains embedded in fibers, (E and F) Au-PS, gold nanoparticles are affixed onto the surface of the fibers.

\subsection{Cytocompatibility of the different types of fibers}

Proliferation of hMSC on the different types of scaffolds at days 1 , 3 , and 7 is shown Fig. 3. The number of cells increased on all scaffolds from the first to the seventh day. At day 1, there was a significant reduction in the number of cells on Au-PS scaffolds compared to PS scaffolds. At day 3, cells proliferated significantly more on the PS scaffolds $(\mathrm{p}<0.01)$. At day 7 , the number of cells was significantly higher on the $\beta$-TCP-PS scaffolds than on the PS $(p<0.05)$ and Au-PS scaffolds $(\mathrm{p}<0.01)$. At each time point, cell proliferation appeared lower on the Au-PS scaffolds than on the other ones.

\subsection{MicroCT analysis}

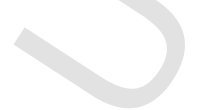

MicroCT 3D analysis of the inner face of the calvaria allowed to identify the initial margins of the bone defect (Fig. 4). No abnormal bone resorption or remodeling was observed. Presence of newly-formed bone was observed in the defect and reflected the proportion of filling the drilled hole according to the type of scaffold. Values of $\mathrm{BAr} / \mathrm{TAr}$ in the different groups are illustrated in Fig. 5. At any time point, the amount of newly-formed bone was significantly higher in the $\beta$-TCP-PS group. A limited bone formation occurred in the Au-PS group at 9 weeks. New bone appeared to be laid down from the margins of the calvarial defect in a centripetal way, suggesting an osteoconduction process (Fig. 4).

\subsection{Histology}

The grafted areas were easily observed on coronal sections of the calvaria. Fig. 6 represents the histological aspects at low magnification observed in each group at 9 weeks. In the control group, the defect was filled by a thin layer of connective fibrous tissue, with no newly-formed bone even after 12 weeks. Calvarial defect filled with an Au-PS scaffold exhibited dense connective tissue. No inflammatory reaction was observed in contact with the biomaterial. Giant cells were never observed around the PS fibers. AuNPs were identified as black particles; they were observed immobilized along some 

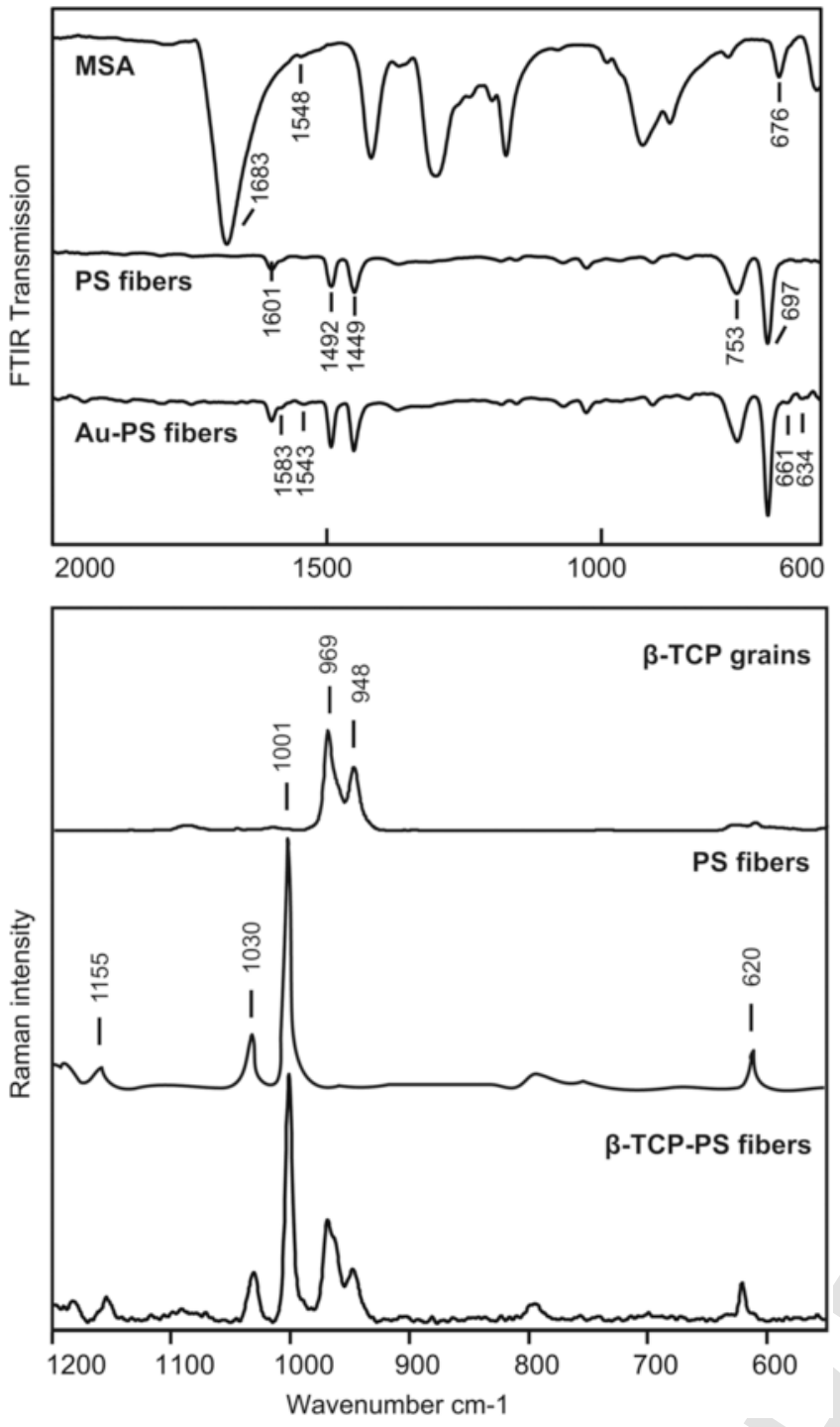

Fig. 2. FTIR and Raman spectra of Au-PS and $\beta$-TCP-PS fibers respectively. Upper panel: FTIR spectra of MSA and PS alone are figured. The spectrum of the Au-PS fibers shows characteristic peaks for both MSA and PS. Lower panel: Raman spectra of pure $\beta$-TCP grains and PS; the last spectrum reveals characteristic peaks of both $\beta$-TCP and PS in $\beta$-TCP-PS fibers.

PS fibers, but most of them were packed together in large aggregates in the fibrosis. Occasionally, packets of newly-formed bone were found to have encapsulated some Au aggregates inside the bone matrix (Fig. 7). In the calvaria grafted with $\beta$-TCP-PS, the defects were filled with dense fibrous connective tissue without inflammatory reaction nor giant cell in contact with the fibers. Numerous fibroblast nuclei were observed between the collagen fibers. Blood vessels were identified in the fibrotic areas which appeared composed of collagen fibers mixed with the $\beta$-TCP-PS fibers. New bone was observed extending from the margins of the defect and covering the surface of the fibrosis at each time of analysis. PS fibers were visible both in the fibrosis and in the newly-formed bone (Fig. 8). They appeared as unstained, non-birefringent ghost structures between the fibroblasts and the collagen fibers. Under polarized light, lamellar bone packed with areas of woven bone was evidenced in the newly-formed bone areas. $\beta$-TCP granules could not be evidenced after the decalcification procedure.

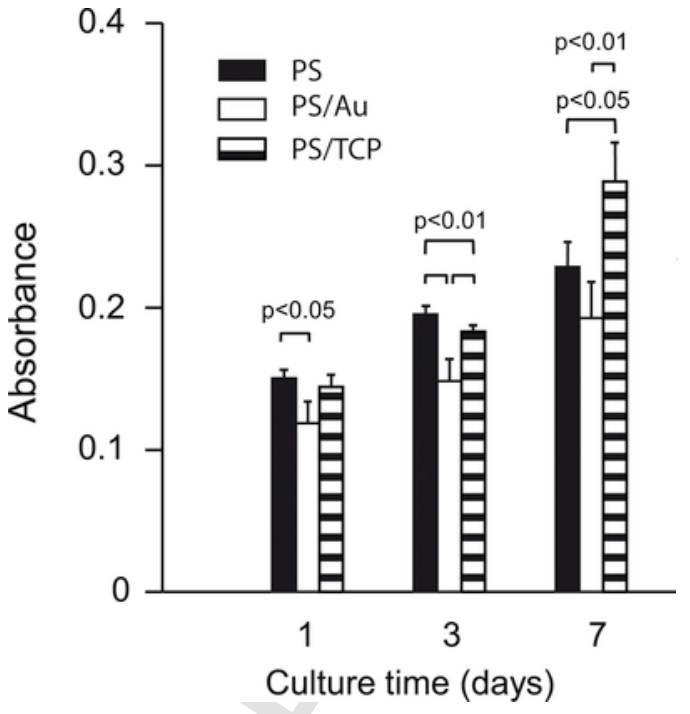

Fig. 3. Proliferation of hMSC cultured on the three different scaffolds: PS, Au-PS, and $\beta$-TCP-PS at 1,3 and 7 days. The initial concentration of cells seeded was $2 \times 10^{4}$ cells $\mathrm{mL}$. Results are expressed in absorbance. Mean for $\mathrm{n}=3 \pm \mathrm{SD}$, significant at $\mathrm{p}<0.05$.

\section{Discussion}

Design and fabrication of scaffolds which could ensure an optimal cell adhesion, spreading, proliferation and differentiation are a challenge for a bone substitute. Surface topography is a well-recognized key factor. Porosity, pore size and interconnected pores are important features which determine cell infiltration into scaffolds of electrospun fibers (Pham et al., 2006). Moreover, interconnected macro-pores are necessary to promote sufficient vascularization into the scaffold to diffuse oxygen, and to transport nutrients and cell progenitors in such scaffolds (Jang et al., 2009; Rouwkema et al., 2008). In this study, a critical-size calvarial defect model was used. It showed no tendency to spontaneous healing, as only a thin collagenous membrane was obtained covering the drilled area at all times of analysis. Two types of electrospun microfibers were used in the animal study in order to characterize their biocompatibility and osteogenic properties. Electrospinning produces well-controlled 3D PS scaffolds with $4 \mu \mathrm{m}$ aligned microfibers. Electrospinning conditions to obtain suitable PS fibers in the micrometer range were previously reported (Terranova et al., 2016). The flow rate and polymer concentration are recognized to have major influences on the morphology and diameter of the fibers (Lim and Mao, 2009). Microfibers were chosen because an increase in the fiber diameter produces enlarged pores. There is a significant relationship between the pore size of electrospun scaffolds and the diameter of the fibers (Eichhorn and Sampson, 2005). Several studies have shown that cell penetration into a scaffold increases with the fiber diameter (Balguid et al., 2008; Sisson et al., 2010). In an in vitro study, the density of MC3T3 cells was found higher on large diameter fibers $(2.1 \mu \mathrm{m})$ than thinner fibers $(0.14 \mu \mathrm{m})$ (Badami et al., 2006).

In our study, we developed PS scaffolds combined with AuNPs or $\beta$-TCP grains to increase osteogenesis and osteoconduction. Calcium-phosphate grains blended with polymer scaffolds are recognized to improve in vitro cell proliferation and differentiation (Lao et al., 2011; McCullen et al., 2009; Wutticharoenmongkol et al., 2007). Similarly, it was shown that carboxylated-AuNPS coated on polymer substrate promotes formation of hydroxyapatite (Vasile et al., 2012). AuNPs are non-cytotoxic for human cells (De Jong et al., 2008). We 


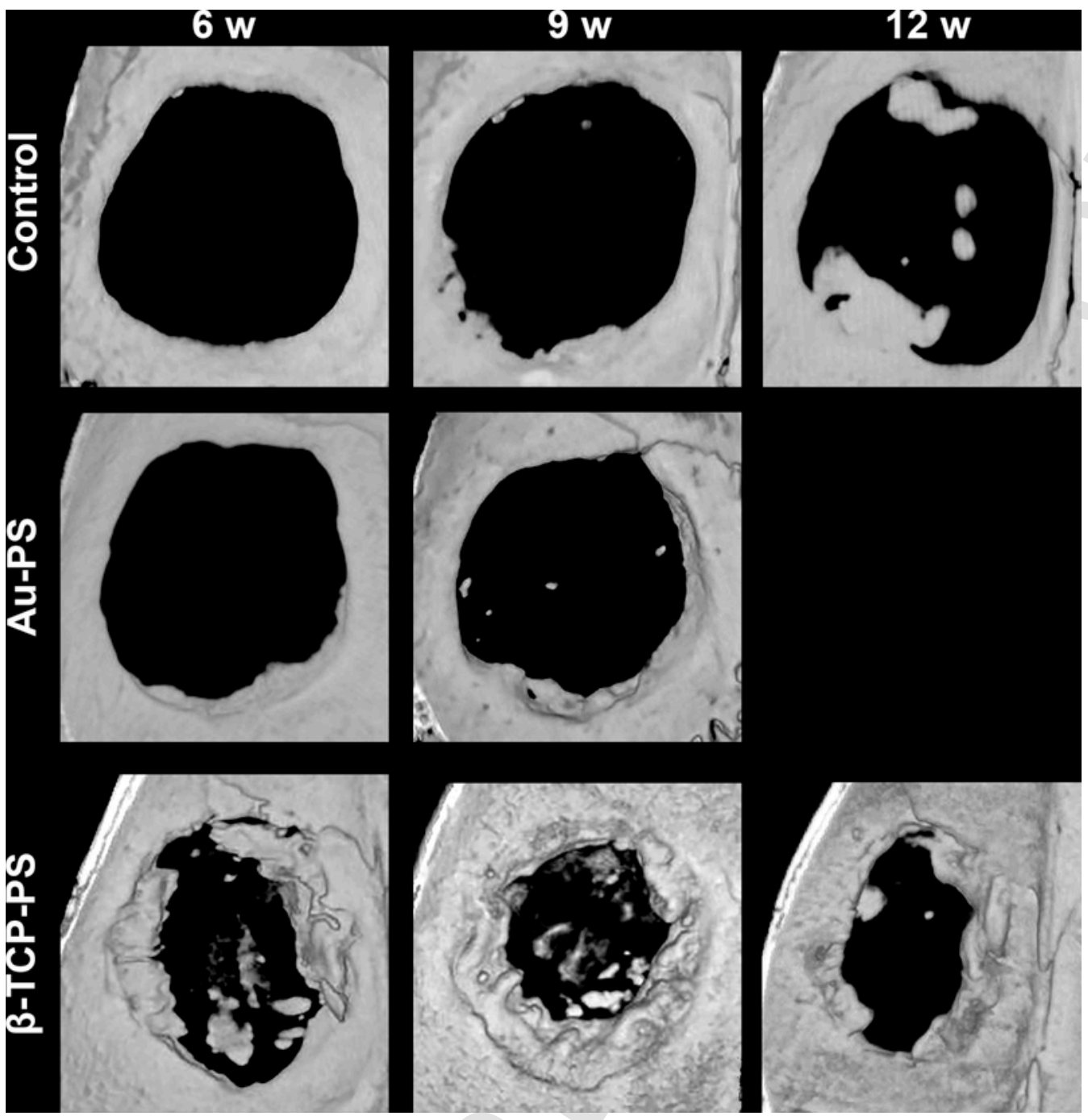

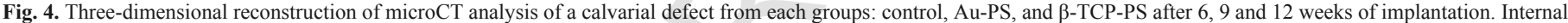
side of calvaria is presented to show the initial defect margin and newly formed bone. Results for Au-PS at 12 weeks are missing.

confirmed the presence of $\beta$-TCP grains at the surface of PS fibers by SEM and Raman microspectroscopy. Similarly, AuNPs were evidenced by SEM and their deposition at the surface of PS fibers was confirmed by FTIR. PS fibers blended with $\beta$-TCP had a rough surface, a well-recognized factor in cell adherence and spreading (Buser et al., 1991; Degasne et al., 1999). Au-PS fibers had a lower surface roughness in SEM.

In this study, proliferation was determined in vitro on PS, $\beta$-TCP-PS and Au-Ps scaffolds to evaluate the cytocompatibility. Cell proliferation was significantly higher on the $\beta$-TCP-PS scaffold than on PS or Au-PS. The surface roughness and the bioactivity of $\beta$-TCP may account for the improved capacity of these scaffolds to favor cytocompatibility. In addition, vitronectin (a glycoprotein essential to the initial attachment of cells) is contained in FBS. It was found that vitronectin could adsorb to PS in variable amounts depending on the polymer surface (Steele et al., 1994). This can explain the differences in cell activity on the different scaffolds. Similarly, attachment of osteoblasts in vitro on hydroxyapatite-coated polystyrene disks was found to rely on vitronectin (Goldberg et al., 2010). Vitronectin is also found in sites of bone damage associated with a local hemorrhage, it could be an important factor for osseointegration of PS scaffolds.
MicroCT and histologic analysis are complementary methods to investigate cell response during the bone healing period after implantation. MicroCT allows a morphologic and quantitative analysis of the new bone formation while cellular environment can only be evaluated histologically. Au-PS scaffolds resulted in a limited bone formation at any time. $\beta$-TCP-PS scaffolds induced more new bone formation starting from the margins to the center of the defect, at each time point. It is likely that $\beta$-TCP has promoted osteoconductivity, as described in other in vivo studies of bone reconstruction obtained with the same animal model (Montjovent et al., 2007; Shim et al., 2012). On histological sections, defects grafted with Au-PS and $\beta$-TCP-PS were filled with a dense fibrous connective tissue incorporating the microfibers. New bone formation was observed under polarized light on picrosirius red stained sections and revealed the formation of lamellar and woven bone. Numerous blood vessels were present into the fibrosis but no inflammatory foci were noted. PS fibers were embedded into the connective tissue or the newly formed bone. PS is not biodegradable and this may be of interest in some particular clinical cases such as oncology (Serafim et al., 2014). In defects grafted with an Au-PS scaffold, most AuNPs seemed to have been removed from the fibers and were accumulated into the connective tissue or the newly-formed bone. It was reported that AuNPs in 


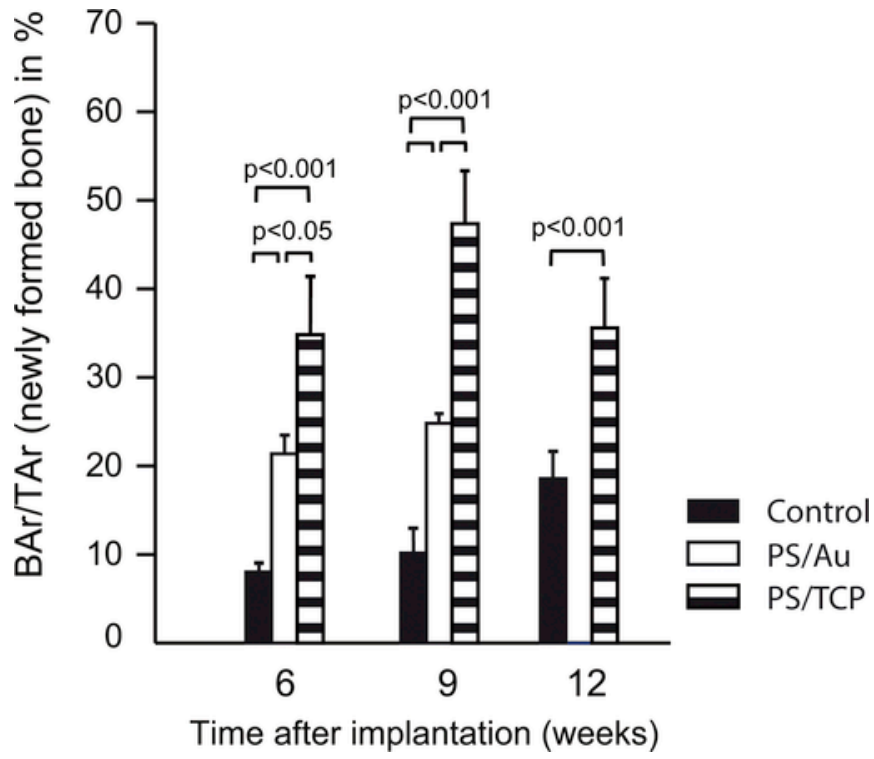

Fig. 5. Newly-formed bone surface filling the calvarial defect: BAr/TAr (\%) measured on the microCT images at 6,9 and 12 weeks after implantation. $\beta$-TCP-PS induced a significantly higher amount of newly-formed bone than Au-PS and control groups at each time point. Results for Au-PS at 12 weeks are missing.

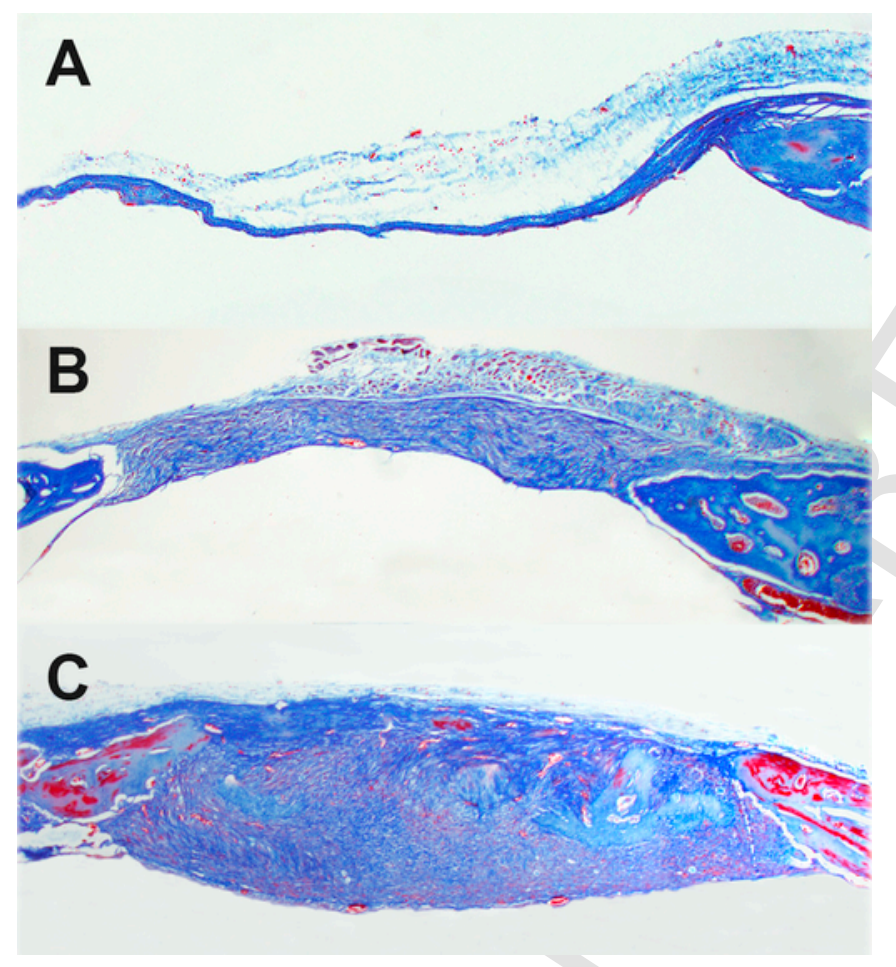

Fig. 6. Coronal section through calvarial defect at 9 weeks stained with Masson's trichrome: (A) control, (B) Au-PS and (C) $\beta$-TCP-PS groups. In the control group, the defect is filled with a thin layer of connective tissue while dense fibrous connective tissue is observed in the other groups. Areas with mineralized tissue are noticed into the defect for $\beta$-TCP-PS group. Magnification: $\times 40$. contact with cells are absorbed by endocytosis and formed aggregates in macrophage lysosomes without eliciting an inflammatory reaction (Shukla et al., 2005).

PS is a well-known cytocompatible polymer. It is extensively used for in vitro studies as constituent of tissue culture plates or Petri's dishes. PS fibers have been found to promote in vitro cell proliferation (Serafim et al., 2014) and differentiation (Terranova et al., 2016) of osteoblast-like cells. In the present study, hMSC grew up from 1 to 7 days on the different types of scaffolds, confirming the excellent cytocompatibility of PS. However, the best results were obtained when a calcium/phosphate biomaterial was added. Therefore, we deliberately chose not to experiment the scaffolds made of PS fibers alone in vivo.

In vivo, the implanted PS fibers appeared biotolerated since they were incorporated into collagenous fibers and newly-formed bone (Donath et al., 1992; Heimke, 1990). Biotolerance is the first degree of biocompatibility and can be accompanied by a limited bone formation. No cluster of inflammatory and giant cells was noted and a direct contact of the fibroblasts with the fibers was evidenced histologically. However, osseointegration of the different PS scaffolds was incomplete even after 12 weeks. Among the limitations of this study, the group of mice with Au-PS scaffold at 12 weeks could not be analyzed; however, the data obtained in cell culture and in vivo at 6 weeks indicate that the AuNPs did not contribute to any significant improvement of the scaffold.

\section{Conclusion}

In this study, PS scaffolds, combined with $\beta$-TCP grains or functionalized gold nanoparticles, were developed by electrospinning. We showed that incorporation of $\beta$-TCP increased cell proliferation in vitro. Bioactivity of $\beta$-TCP and the surface roughness of the $\beta$-TCP-PS fibers improved cytocompatibility. Biocompatibility and bone repair were studied after implantation of scaffolds into calvarial defects. $\beta$-TCP-PS showed a greater new bone formation than Au-PS but the healing of the defect remained incomplete. AuNPs detached from the fibers and accumulated into fibrous tissue and new bone. PS fibers were encapsulated into fibrosis without inflammatory and giant cells. This study stresses the differences that can be obtained with a biomaterial that is well cytocompatible in vitro but is only biotolerated in vivo.

\section{Conflict of interest}

Authors have no conflict of interest.

\section{Acknowledgments}

This work was made possible by grants from ANR, program LabCom "NextBone" (France). The authors thank Kasios, 18 chemin de la Violette, 31240 L'Union - France for providing the $\beta$-TCP grains. Stancu, Dragusin and Vasile gratefully acknowledge the support from the project PNII PCCA 183/2012 (Romania). The authors also thank Jérôme Duisit from Pôle de Morphologie at UCL for his advice and providing the human mesenchymal stem cells and Baptiste Arbez for his help with Raman analysis. L. Terranova received an Erasmus Mundus Ph.D. scholarship (program Nanofar). 

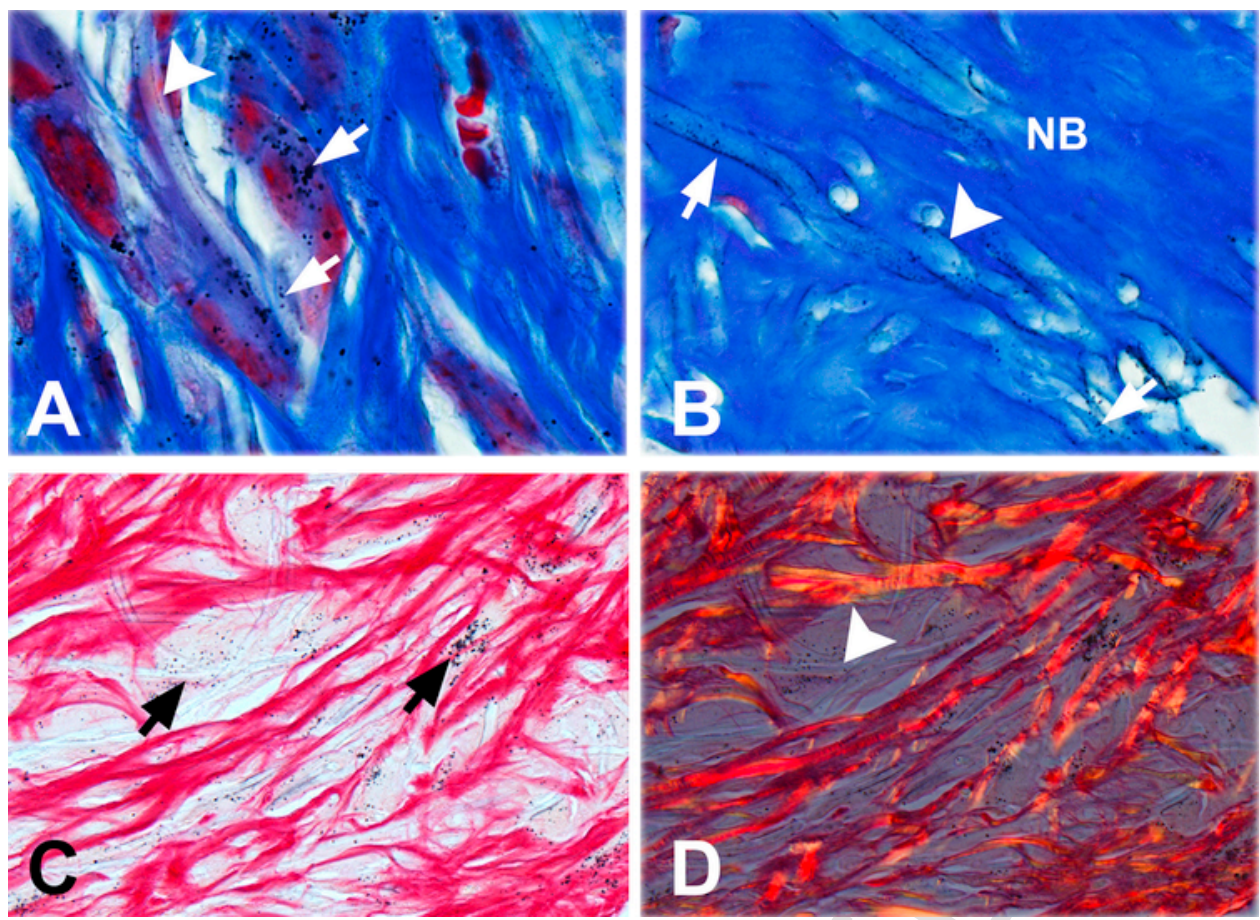

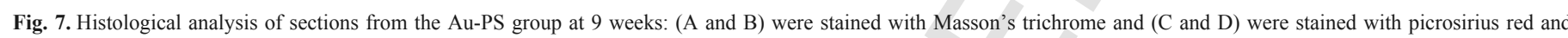

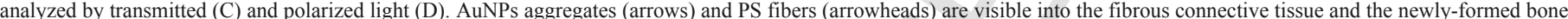

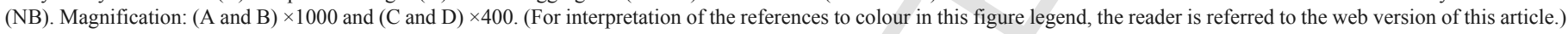
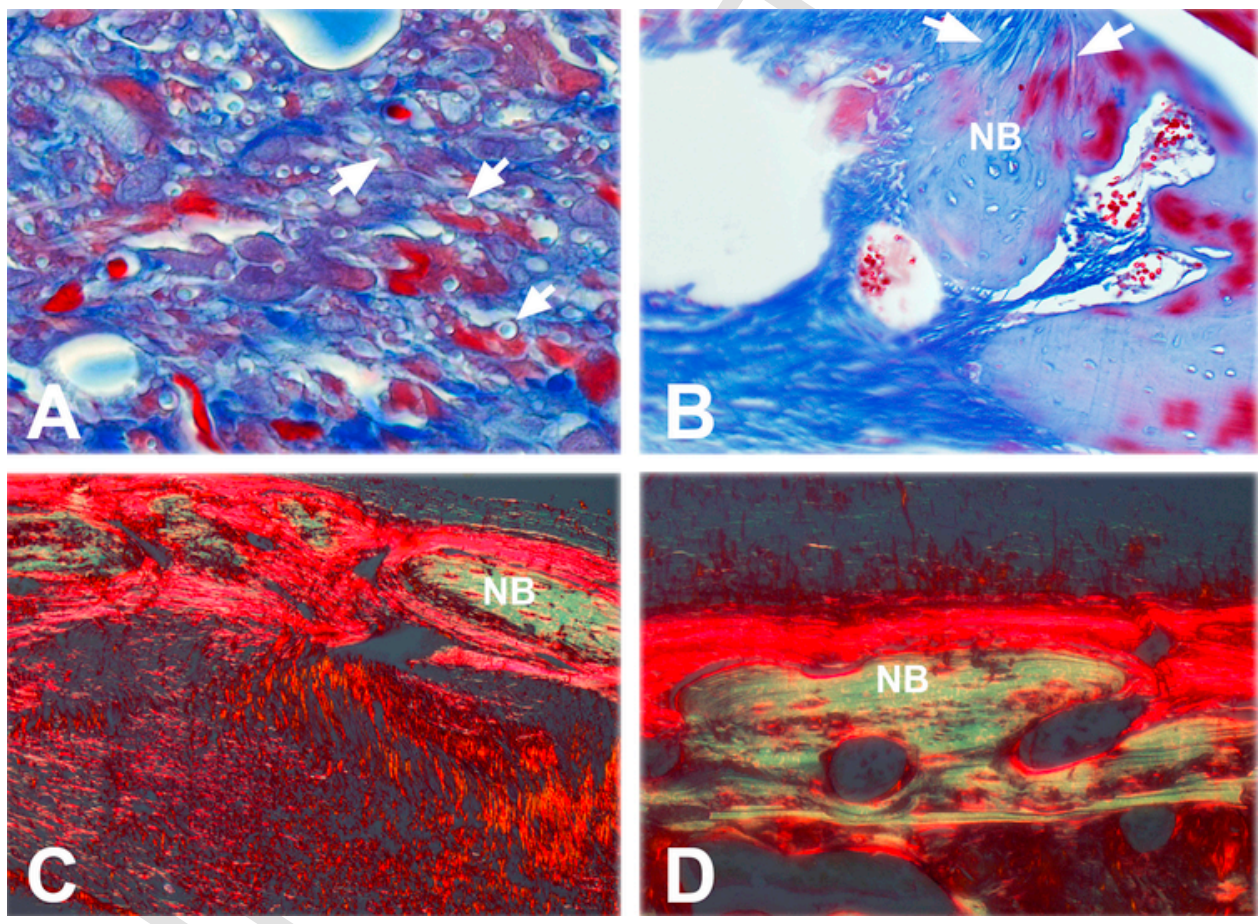

Fig. 8. Histological analysis of sections from the $\beta$-TCP-PS group at 9 weeks: (A and B) were stained with Masson's trichrome and (C and D) were stained with picrosirius red and analyzed under polarized light. PS fibers (arrows) were included into dense fibrous connective tissue and new bone (NB). Note the new lamellar bone visible in polarized light (C and D). Magnification: (A) $\times 1000$, (B and C) $\times 200$, (D) $\times 400$. (For interpretation of the references to colour in this figure legend, the reader is referred to the web version of this article.) 


\section{References}

An, Y.H., Freidman, R.J., 1999. Animal models of bone defect repair. In: An, Y.H., Freidman, R.J. (Eds.), Animal Models in Orthopaedic Research. CRC Press, Boca Raton, pp. 241-260.

Badami, A.S., Kreke, M.R., Thompson, M.S., Riffle, J.S., Goldstein, A.S., 2006. Effect of fiber diameter on spreading, proliferation, and differentiation of osteoblastic cells on electrospun poly (lactic acid) substrates. Biomaterials 27, 596-606.

Baker, S.C., Atkin, N., Gunning, P.A., Granville, N., Wilson, K., Wilson, D., Southgate, J., 2006. Characterisation of electrospun polystyrene scaffolds for three-dimensional in vitro biological studies. Biomaterials 27, 3136-3146.

Balguid, A., Mol, A., van Marion, M.H., Bank, R.A., Bouten, C.V., Baaijens, F.P., 2008. Tailoring fiber diameter in electrospun poly ( $\varepsilon$-caprolactone) scaffolds for optimal cellular infiltration in cardiovascular tissue engineering. Tissue Eng. Part A $15,437-444$.

Brandi, M.L., Collin-Osdoby, P., 2006. Vascular biology and the skeleton. J. Bone Miner. Res. 21, 183-192.

Buser, D., Schenk, R., Steinemann, S., Fiorellini, J., Fox, C., Stich, H., 1991. Influence of surface characteristics on bone integration of titanium implants. A histomorphometric study in miniature pigs. J. Biomed. Mater. Res. 25, 889-902.

Chappard, D., Guillaume, B., Mallet, R., Pascaretti-Grizon, F., Baslé, M.F., Libouban, H., 2010. Sinus lift augmentation and beta-TCP: a microCT and histologic analysis on human bone biopsies. Micron 41, 321-326.

De Jong, W.H., Hagens, W.I., Krystek, P., Burger, M.C., Sips, A.J., Geertsma, R.E., 2008. Particle size-dependent organ distribution of gold nanoparticles after intravenous administration. Biomaterials 29, 1912-1919.

Degasne, I., Baslé, M.F., Demais, V., Huré, G., Lesourd, M., Grolleau, B., Mercier, L., Chappard, D., 1999. Effects of roughness, fibronectin and vitronectin on attachment spreading, and proliferation of human osteoblast-like cells (Saos-2) on titanium surfaces. Calcif. Tissue Int. 64, 499-507.

Dempster, D.W., Compston, J.E., Drezner, M.K., Glorieux, F.H., Kanis, J.A., Malluche, H., Meunier, P.J., Ott, S.M., Recker, R.R., Parfitt, A.M., 2013. Standardized nomenclature, symbols, and units for bone histomorphometry: a 2012 update of the report of the ASBMR Histomorphometry Nomenclature Committee. J. Bone Miner. Res. 28, 2-17.

Dimitriou, R., Mataliotakis, G.I., Angoules, A.G., Kanakaris, N.K., Giannoudis, P.V., 2011. Complications following autologous bone graft harvesting from the iliac crest and using the RIA: a systematic review. Injury 42, S3-S15.

Donath, K., Laß, M., Günzl, H.-J., 1992. The histopathology of different foreign-body reactions in oral soft tissue and bone tissue. Virchows Arch. A 420, 131-137.

Eichhorn, S.J., Sampson, W.W., 2005. Statistical geometry of pores and statistics of porous nanofibrous assemblies. J. R. Soc. Interface 2, 309-318.

Goldberg, A.J., Liu, Y., Advincula, M.C., Gronowicz, G., Habibovic, P., Kuhn, L.T., 2010. Fabrication and characterization of hydroxyapatite-coated polystyrene disks for use in osteoprogenitor cell culture. J. Biomater. Sci. Polym. Ed. 21, 1371-1387.

Heimke, G., 1990. The aspects and modes of fixation of bone replacements. In: Heimke, G. (Ed.), Osseo-Integrated Implants. CRC Press, Boca Raton, Ann Arbor, Boston, pp. 1-29.

Jang, J.-H., Castano, O., Kim, H.-W., 2009. Electrospun materials as potential platforms for bone tissue engineering. Adv. Drug Deliv. Rev. 61, 1065-1083.

Lao, L., Wang, Y., Zhu, Y., Zhang, Y., Gao, C., 2011. Poly (lactide-co-glycolide)/hydroxyapatite nanofibrous scaffolds fabricated by electrospinning for bone tissue engineering. J. Mater. Sci. Mater. Med. 22, 1873-1884.
Lim, S.H., Mao, H.-Q., 2009. Electrospun scaffolds for stem cell engineering. Adv. Drug Deliv. Rev. 61, 1084-1096.

Ma, Z., Kotaki, M., Inai, R., Ramakrishna, S., 2005. Potential of nanofiber matrix as tissue-engineering scaffolds. Tissue Eng. 11, 101-109.

McCullen, S., Zhu, Y., Bernacki, S., Narayan, R., Pourdeyhimi, B., Gorga, R., Loboa, E., 2009. Electrospun composite poly (L-lactic acid)/tricalcium phosphate scaffolds induce proliferation and osteogenic differentiation of human adipose-derived stem cells. Biomed. Mater. 4, 035002.

Montjovent, M.O., Mathieu, L., Schmoekel, H., Mark, S., Bourban, P.E., Zambelli, P.Y., Laurent-Applegate, L.A., Pioletti, D.P., 2007. Repair of critical size defects in the rat cranium using ceramic-reinforced PLA scaffolds obtained by supercritical gas foaming. J. Biomed. Mater. Res. Part A 83, 41-51.

Park, H.J., Min, K.D., Lee, M.C., Kim, S.H., Lee, O.J., Ju, H.W., Moon, B.M., Lee, J.M., Park, Y.R., Kim, D.W., 2016. Fabrication of 3D porous SF/ $\beta$-TCP hybrid scaffolds for bone tissue reconstruction. J. Biomed. Mater. Res. Part A $104,1779-1787$.

Pham, Q.P., Sharma, U., Mikos, A.G., 2006. Electrospun poly ( $\varepsilon$-caprolactone) microfiber and multilayer nanofiber/microfiber scaffolds: characterization of scaffolds and measurement of cellular infiltration. Biomacromolecules 7, 2796-2805.

Rouwkema, J., Rivron, N.C., van Blitterswijk, C.A., 2008. Vascularization in tissue engineering. Trends Biotechnol. 26, 434-441.

Serafim, A., Mallet, R., Pascaretti-Grizon, F., Stancu, I.C., Chappard, D., 2014. Osteoblast-like cell behavior on porous scaffolds based on poly(styrene) fibers. Biomed. Res. Int. 2014, 609319.

Shim, J.-H., Moon, T.-S., Yun, M.-J., Jeon, Y.-C., Jeong, C.-M., Cho, D.-W., Huh, J.-B., 2012. Stimulation of healing within a rabbit calvarial defect by a PCL/PLGA scaffold blended with TCP using solid freeform fabrication technology. J. Mater. Sci. Mater. Med. 23, 2993-3002.

Shukla, R., Bansal, V., Chaudhary, M., Basu, A., Bhonde, R.R., Sastry, M., 2005. Biocompatibility of gold nanoparticles and their endocytotic fate inside the cellular compartment: a microscopic overview. Langmuir 21, 10644-10654.

Sisson, K., Zhang, C., Farach-Carson, M.C., Chase, D.B., Rabolt, J.F., 2010. Fiber diameters control osteoblastic cell migration and differentiation in electrospun gelatin. J. Biomed. Mater. Res. Part A 94, 1312-1320.

Sperling, R.A., Gil, P.R., Zhang, F., Zanella, M., Parak, W.J., 2008. Biological applications of gold nanoparticles. Chem. Soc. Rev. 37, 1896-1908.

Steele, J.G., McFarland, C., Dalton, B.A., Johnson, G., Evans, M.D., Rolfe Howlett, C., Underwood, P.A., 1994. Attachment of human bone cells to tissue culture polystyrene and to unmodified polystyrene: the effect of surface chemistry upon initial cell attachment. J. Biomater. Sci. Polym. Ed. 5, 245-257.

Storhoff, J.J., Elghanian, R., Mucic, R.C., Mirkin, C.A., Letsinger, R.L., 1998. One-pot colorimetric differentiation of polynucleotides with single base imperfections using gold nanoparticle probes. J. Am. Chem. Soc. 120, 1959-1964.

Terranova, L., Mallet, R., Perrot, R., Chappard, D., 2016. Polystyrene scaffolds based on microfibers as a bone substitute; development and in vitro study. Acta Biomater. 29, 380-388.

Vasile, E., Serafim, A., Dragusin, D.-M., Petrea, C., Iovu, H., Stancu, I.-C., 2012. Apatite formation on active nanostructured coating based on functionalized gold nanoparticles. J. Nanopart. Res. 14, 1-14.

Wutticharoenmongkol, P., Pavasant, P., Supaphol, P., 2007. Osteoblastic phenotype expression of MC3T3-E1 cultured on electrospun polycaprolactone fiber mats filled with hydroxyapatite nanoparticles. Biomacromolecules 8, 2602-2610.

Younger, E.M., Chapman, M.W., 1989. Morbidity at bone graft donor sites. J. Orthop. Trauma 3, 192-195. 